\title{
Removal of Heavy Metal from Contaminated Soil with Chelating Agents
}

\author{
Wei Jiang $^{1 *}$, Tao Tao ${ }^{1}$, Zhiming Liao ${ }^{2}$ \\ ${ }^{1}$ Department of Environmental Science \& Engineering Huazhong University of Science and Technology, Wuhan, China; ${ }^{2}$ Jiangxi \\ JDL Environmental Protection Research Ltd., Changleng Overseas Investment Zone Nanchang, Nanchang, China. \\ Email: *jw0707@163.com
}

Received August $4^{\text {th }}, 2011$; revised August 25 ${ }^{\text {th }}, 2011$; accepted August $30^{\text {th }}, 2011$.

\begin{abstract}
Removal of copper and nickel by the addition of the biodegradable chelating agent, chitosan and ethylenediamine tetraacetic acid (EDTA), was investigated, alongside the reaction of a reference compound sodium citrate for comparison. The artificial-contaminated soils were used in this study. The experiments showed that the extraction ability for copper and nickel from the contaminated soil decreased as follows: chitosan > EDTA > sodium citrate. The pH value of the eluents is the key to control the extraction, especially to chitosan solution. It was evident that the chitosan solution was the most efficient when the pH value was $3-3.5$, the rate of extraction of copper being $43.36 \%$ and of nickel being $37.07 \%$. And the best match of concentration and liquid/solid was $0.3 \mathrm{~g} / \mathrm{L}$ and $10 \mathrm{~mL} / \mathrm{g}$.
\end{abstract}

Keywords: Chemical Extraction, Soil Remediation, Copper, Nickel, Chitosan, EDTA, Sodium Citrate

\section{Introduction}

Remediation methods of contaminated soils with heavy metals can be roughly classified into physical or chemical, and phytoremediation [1]. Remediation mechanisms basically consist of two fundamental principles. The first is to completely remove contaminations from polluted sites and the second is to transform these pollutants to harmless forms by using one or more engineering tech- nologies, which mainly include excavation, separation, extraction, electrokinesis, washing, oxidation, reduction, phytoextraction, phytovolatilization, or solidification, vitrification, among others [1-4].

Traditionally, remediation of contaminated soils is achieved by excavation and ex situ treatment (generally solidification/stabilization) and/or disposal. [5,6]. The remedial actions based on solidification/stabilization technology are no longer considered a permanent environmental solution because of: 1) the metals are not removed from contaminated media; 2) the need for future monitoring of heavy metals on site; 3) questionable longevity of the solidified/stabilized materials; and 4) the long-term management of the solidified/stabilized materials is based on landfilling and requires soil caps to prevent erosion problems [7]. The high cost and disruption of such treatments has made the development of in situ alternatives $[6,8]$. Thus, several methods for in situ remediation have been developed, including vitrification, soil washing/acid extraction, phytoremediation, soil flushing [9], and bioremediation [10-12]. However, there are still several disadvantages associated with phytoremediation, electro-kinetics and bioremediation. Those were long treatment duration, subjectivity to weather patterns, plant predation and diseases, potential phytotoxicity when applied in heavily polluted soils, risk of food chain contamination, ineffectiveness in extracting the strongly bound contaminants, suitable micro-organisms, environmental conditions and time, and finally risk of leaching of pollutants. Hence, there is a great need to promote effective soil treatment technologies that attempts to remove the metals from the soils. Among these developed remediation technologies, soil washing process gives high removal efficiency for remediating sites contaminated by heavy metals and organics using suitable chelating agents, surfactant, acids, alkalis and complexing agents because it can be applied to large contaminated areas due to its rapid kinetics, operational easiness, and economical efficiency [13]. Several types of extractants can be used to extract heavy metals and metalloids from contaminated soils for soil washing technology. The extractants may be acids, bases, chelating agents, electrolytes, oxidizing agents and surfactants [14-17], of which acids and chelating agents are the most 
popular extractive reagents for heavy metals decontamination. Acid washing leads to decreased soil productivity and adverse changes in the chemical and physical structures of soils due to mineral dissolution [18]. Chelating agents such as ethylenediamine tetraacetic acid (EDTA), nitriloacetic acid (NTA), diethylenetriamine pentaacetic acid (DTPA) and S,S-ethylene-diaminedisuccinic acid (EDDS) are regarded as more attractive alternatives to acids or bases because they can form strong metal-ligand complexes and are thus highly effective in remediating heavy metal-contaminated soils [19-21]. Among these chelators, NTA is a Class II carcinogen [22] and DTPA is identified by Sigma Chemical Co. (St. Louis, MO) as toxic and a potential carcinogen [23]. EDTA continues to be explored extensively for soil remediation because of its ability to mobilize metal cations efficiently coupled with only a minor impact on the physical and chemical properties of the soil matrix [24]. The extraction kinetics of copper, zinc, iron and manganese from the contaminated sediment of the Clark Fork River in western Montana, U.S.A., with Disodiun Ethylenediaminetetraacetate $\left(\mathrm{Na}_{2}\right.$ EDTA) as the extraction agent, were investigated. The results showed the extraction process consisted of rapid extraction in the first minutes followed by much slower extraction for the remainder of the experiment. The rate of extraction, particularly in the rapid phase, demonstrated clear $\mathrm{pH}$ dependence: the lower the $\mathrm{pH}$, the faster the extraction rate [38].

Previous study has proved that some chelating agents, such as EDTA, DTPA, and EDDS, were suitable to remediate the metal-contaminated soils. However, Little information is available in using chitosan, the common and biodegradable chelate compound, as the chelating agent to separate the heavy metal from the soil. The aim of this study was to verify the capacity of chitosan for removal of copper and nickel from the soil after a conventional soil wash procedure. A batch study using solutions of the two chelating agents (chitosan, EDTA), and sodium citrate as a reference for comparison, was performed. The key issues were: 1) Which is the most effective eluent for the copper/nickel contaminated soil? 2) Which is the most important parameter to control the extracting reaction? 3) What are the optimal parameters?

\section{Material and Method}

\subsection{Soil}

The soil investigated in this study was obtained from $0 \mathrm{~m}$ - $1.5 \mathrm{~m}$ below the ground surface in the area of changleng high-tech industrial development zone, Nanchang city of China. The soil sample was belong to red earth and was initially uncontaminated with toxic heavy metals. All the soil samples were air dried, screened through
Number 10 sieve to remove large particles and stones, then thoroughly mixed to ensure uniformity and stored in a plastic bag at room temperature $\left(20^{\circ} \mathrm{C}-30^{\circ} \mathrm{C}\right)$ for subsequent experiments.

\subsection{Soil Contamination}

Two soil samples, which were $1 \mathrm{Kg}$ weight, were taken from the prepared soil, and were spiked with solutions containing $\mathrm{CuSO}_{4}$ or $\mathrm{NiSO}_{4}$, separately. The laboratoryprepared contaminated soil had the advantage of good homogeneity in terms of consistent heavy metal concentration and speciation, soil composition, contamination process, and contamination period. This would minimize ambiguity in the extraction results arising from sample heterogeneity. To minimize the discrepancy between the field-contaminated soil and the artificial-contaminated soil, the soil samples were equilibrated for 2 weekss in wet condition followed by dry aging for more than 4 weeks. The wet aging stage was essential to ensure complete and even exposure of every soil particle to contamination. At the end of the 2-week wet-aging period, the soils were separated from solution, dried and aged further for another 4 weeks before soil characterization and extraction experiment were carried out.

The following parameters were determined prior to the extraction experiments: $\mathrm{pH}$ (solid: de-ironed water $=1$ : $2.5 \mathrm{~W} / \mathrm{V}$ ); water content; specific gravity; total organic matter; total nickel and copper contents (mixed acid digestion with concentrated $\mathrm{HNO}_{3}, \mathrm{HCl}, \mathrm{HF}$ and $\mathrm{HClO}_{4}$ ). The selected physicochemical properties of the sample soils are presented in Table 1.

\subsection{Analysis of Metal Sepciation}

Copper and nickel speciations in the contaminated soil were performed using sequential extraction based on Tessier procedure [25]. The exchangeable fraction was determined through extraction with $8 \mathrm{~mL}$ of $1.0 \mathrm{M} \mathrm{MgCl}_{2}$ at $\mathrm{pH} 7.0$ for $1 \mathrm{~h}$. The carbonated-associated fraction was determined after extraction with $8 \mathrm{~mL}$ of $1.0 \mathrm{M} \mathrm{NaAc}$ adjusted to $\mathrm{pH} 5.0$ with acetic acid for $5.0 \mathrm{~h}$. The Fe-Mn oxide fraction was determined after extraction with 20

Table 1. Physicochemical properties of the soils used in the study.

\begin{tabular}{cc}
\hline physicochemical properties & value \\
\hline $\mathrm{pH}$ & 5.01 \\
water content & $8.54 \%$ \\
specific gravity & $2.27 \times 10^{3} \mathrm{~kg} / \mathrm{m}^{3}$ \\
total organic matter & $0.17 \%$ \\
total nickel contents & $566 \mathrm{~g} \cdot \mathrm{kg}^{-1}$ \\
total copper contents & $419 \mathrm{~g} \cdot \mathrm{kg}^{-1}$ \\
total Fe contents & $6025 \mathrm{mg} \cdot \mathrm{kg}^{-1}$ \\
\hline
\end{tabular}


$\mathrm{mL}$ of $0.04 \mathrm{M} \mathrm{NH}_{2} \mathrm{HCl}$ in $25 \%$ (v) acetic acid (pH 2.0) for $6.0 \mathrm{~h}$ at $96^{\circ} \mathrm{C}$. The organic fraction was determined after extraction with $3 \mathrm{~mL}$ of $30 \% \mathrm{H}_{2} \mathrm{O}_{2}$ and $0.02 \mathrm{M}$ $\mathrm{HNO}_{3}\left(\mathrm{pH} 2.0\right.$ ) for $2.0 \mathrm{~h}$ at $85^{\circ} \mathrm{C}$, followed by $3 \mathrm{~mL} 30 \%$ (v) $\mathrm{H}_{2} \mathrm{O}_{2}$ (pH 2.0) for $3.0 \mathrm{~h}$ at $85^{\circ} \mathrm{C}$ and then $5 \mathrm{~mL}$ of 3.2 $\mathrm{M} \mathrm{NH}_{4} \mathrm{Ac}$ in $20 \% \mathrm{HNO}_{3}$ diluted to $20 \mathrm{~mL}$ at room temperature for $0.5 \mathrm{~h}$. The residual fraction, the above four fractions subtracted from the total metal content.

\subsection{Eluent Production}

Considering the biodegradation, in this study, chitosan, EDTA and sodium citrate were selected from all kinds of eluents. To product EDTA solution, $0.1 \mathrm{~g}$ of EDTA was dissolved in the $500 \mathrm{ml}$ de-ironizeed water, the same as to product sodium citrate solution. It was different in the processing of preparing the chitosan solution. At first, the $0.1 \mathrm{~g}$ of chitosan must be dissolved in the HCL solution of $0.1 \mathrm{~mol} / \mathrm{L}$, and then the mixed solution was moved into $500 \mathrm{ml}$ volumetric flask, brought to volume by deironized water, and mixed. All the chemicals were procured as analytical grade from China Chemical Factory, Shanghai, China (purity $\geq 99 \%$ ).

\subsection{Extraction procedure}

Five sets of extraction experiments were conducted to assess the effects of 1) chelating agent; 2) reaction time; 3) $\mathrm{pH}$; 4) liquid/solid ratio; and 5) chelating agent concentration on copper/nickel extraction efficiencies. The extraction tests were conducted in $25 \mathrm{~mL}$ polyethylene tubes. The tubes containing $2.0 \mathrm{~g}$ soil sample and a measured volume of chelating agent were agitated using an end-over-end shaker at a speed of $120 \mathrm{rpm}$ at room temperature $\left(28^{\circ} \mathrm{C}-33^{\circ} \mathrm{C}\right)$ for a given time. The suspensions were centrifuged at the rotating speed of $4000 \mathrm{rpm}$ for 15 min and the supernatants were then filtered through a $0.45 \mathrm{~mm}$ membrane to remove particulates in the solution. The residues were washed twice by de-iron water. The supernatants were collected into a $50 \mathrm{~mL}$ flask, brought to volume by de-ironized water, and the concentrations of metals were measured by atomic absorption.

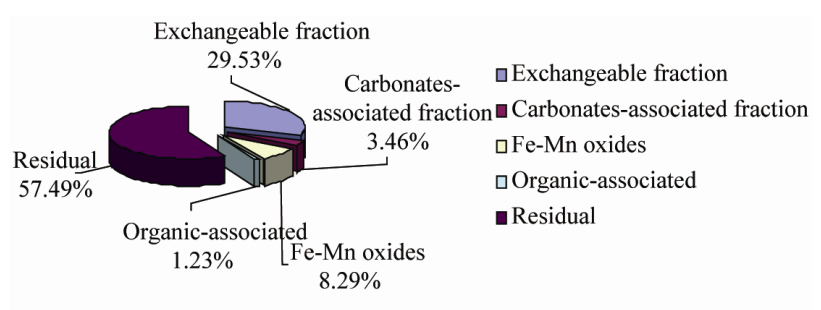

(B) Sequential extraction of metals nickel from contaminated soi

Figure 1. Sequential extraction of metals $(\mathrm{Cu}$ and $\mathrm{Ni})$ from soil samples: Five extraction steps, modified from [25]. The fractions represent mean values, $\mathbf{N}=3$.
Five sets of extraction experiments were conducted to assess the effects of 1) chelating agent; 2) reaction time; 3) $\mathrm{pH}$; 4) liquid/solid ratio; and 5) chelating agent concentration on copper/nickel extraction efficiencies. The extraction tests were conducted in $25 \mathrm{~mL}$ polyethylene tubes. The tubes containing $2.0 \mathrm{~g}$ soil sample and a measured volume of chelating agent were agitated using an end-over-end shaker at a speed of $120 \mathrm{rpm}$ at room temperature $\left(28^{\circ} \mathrm{C}-33^{\circ} \mathrm{C}\right)$ for a given time. The suspensions were centrifuged at the rotating speed of $4000 \mathrm{rpm}$ for 15 min and the supernatants were then filtered through a $0.45 \mathrm{~mm}$ membrane to remove particulates in the solution. The residues were washed twice by de-iron water. The supernatants were collected into a $50 \mathrm{~mL}$ flask, brought to volume by de-ironized water, and the concentrations of metals were measured by atomic absorption spectrophotometer. All tests were performed in triplicates and the results were presented as averages of the triplicate extracts.

In the experiment investigating different chelating agents, three kinds of chelating agents were used: chitosan, ethylenediamine tetraacetic acid (EDTA) and sodium citrate. The $0.2 \mathrm{~g} / \mathrm{L}$ eluent solutions (chitosan/ EDTA/sodium citrate) were prepared according to $\mathbf{2 . 4}$. The final solution $\mathrm{pH}$ of chitosan, EDTA and sodium citrate was $3.27,3.13$ and 7.33 , respectively. The washing times were set from $2 \mathrm{~h}$ to $8 \mathrm{~h}$ for the three types of chelating agents. The treatments had the same concentration $(0.2 \mathrm{~g} / \mathrm{L})$ and liquid/soil ratio $(10 \mathrm{ml} / \mathrm{g})$.

In the $\mathrm{pH}$ value experiment, five different $\mathrm{pH}$ value of chitosan solution $(3,4,5,6,7)$ were chosen $(\mathrm{L} / \mathrm{S}=10$ $\mathrm{ml} / \mathrm{g}, 2 \mathrm{~h}$ ). The $\mathrm{pH}$ values of chitosan solution were adjusted with diluted $\mathrm{HNO}_{3}$ or $\mathrm{NaOH}$ solution. The liquid/ soil ratio investigations were conducted by $1,2,3$ and $4 \mathrm{~g}$ of soil sample with $20 \mathrm{ml} 0.2 \mathrm{~g} / \mathrm{L}$ chitosan solution, giving liquid/soil ratios of $20,10,7$, and 5 , respectively ( $2 \mathrm{~h}$ ). To study the effects of concentration on extraction efficiency, the concentrate of chitosan solution applied were $0.1 \mathrm{~g} / \mathrm{L}, 0.2 \mathrm{~g} / \mathrm{L}, 0.3 \mathrm{~g} / \mathrm{L}$, and $0.4 \mathrm{~g} / \mathrm{L}$, while the soil sample were $1 \mathrm{~g}(\mathrm{~L} / \mathrm{S}=10 \mathrm{ml} / \mathrm{g}, 2 \mathrm{~h})$.

\section{Result and Discuss}

\subsection{Comparing and Selecting of Eluents}

To study the extraction effects of three kinds of eluents used to the contaminated soil, the extraction efficiency has been shown in Figure 2. It was found that, for the eluents tested, the order of extraction of copper and nickel from the heavy metal contaminated soil was chitosan $>$ EDTA $>$ sodium citrate. And the extraction efficiency of nickel was higher than copper, when they were extracted with the same chelating agents. The removal difference was consistent with the relative stability of 


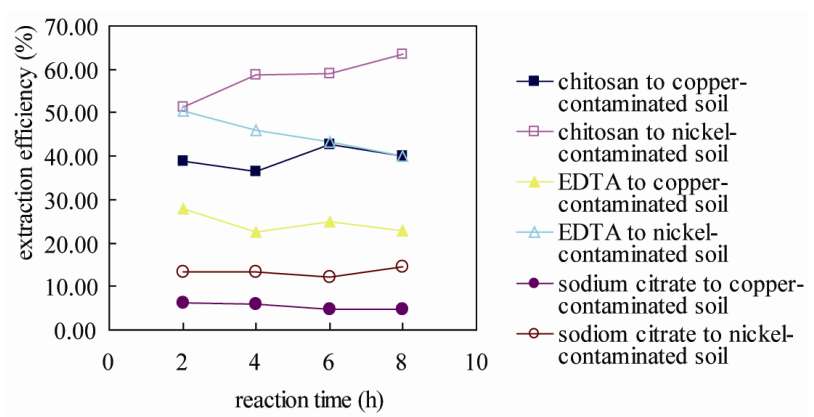

Figure 2. Extraction efficiency of copper/nickel using chitosan solution $(0.2 \mathrm{~g} / \mathrm{L}$, liquid/solid $=10, \mathrm{pH}=3.27)$, EDTA solution $(0.2 \mathrm{~g} / \mathrm{L}$, liquid/solid $=10, \mathrm{pH}=3.06)$, and sodium citrate solution $(0.2 \mathrm{~g} / \mathrm{L}$, liquid/solid $=10, \mathrm{pH}=7.33)$ with different reaction time.

ligand complexes for the two metals [30]. So the chitosan solution was the most effective chelating agent, especially to extract nickel from the nickel-contaminated soil.

It was also evident that extending the reaction time from $2 \mathrm{~h}$ to $8 \mathrm{~h}$ did not affect the extract efficiency significantly, especially to the copper-contaminated soil. While to the nickel-contaminated soil, the extract efficiency increased from $51.25 \%$ to $63.47 \%$. The possible reason lies in the extracted copper/nickel was re-dissolved in the soil in longer reaction time. Considering technique-economy, the optimal reaction time in the extraction was 2 hours. The process of chelating agents extracting heavy metal from the soil included two step adsorptions, in which a rapid desorption within the first hour was followed by a subsequent gradual release that occurred over the following hours [31]. In this study, the removal reached a relatively higher level at $2 \mathrm{~h}$, when $38.72 \%$ of copper and $51.25 \%$ of nickel were removed. With further mixing, the removal approached a plateau after $4-8 \mathrm{~h}$ and remained almost constant. A further increase of the reaction time had little effect on the overall removal. Therefore, a reaction time of $2 \mathrm{~h}$ was chosen for the following experiments.

\subsection{Influence of Chitosan Solution $\mathrm{pH}$ on Copper/Nickel Extraction}

In the $\mathrm{pH}$ value dependent experiment, the extract efficiency decreased with the increasing $\mathrm{pH}$ value of the chitocan solution. It was the highest extract efficiency when the $\mathrm{pH}$ value was 3 (Figure 3). Many studies have shown that $\mathrm{pH}$ is the dominant solution parameter controlling metal extraction from adsorbents [26]. Desorption decreases dramatically as solution $\mathrm{pH}$ increased. It is possible for the presence of complexing ligands to interfere with this relationship [27]. The reason was in relation to the nature that chitosan was a derivative from the

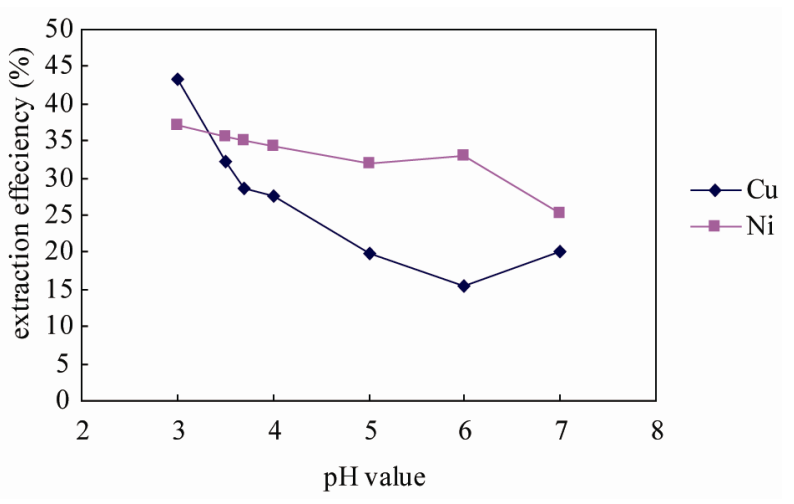

Figure 3. Extraction efficiency of copper/nickel using 0.2 $\mathrm{g} / \mathrm{L}$ chitosan solution with different $\mathbf{p H}$ value (liquid/solid = 10 , reaction time $=2 \mathrm{~h}$ ).

natural amino polysaccharide chitin by stripping acetyl down, and the amino in chitosan can form complexes with metal ions in acidic medium, which was because the amino can be protonated to $\mathrm{R}-\mathrm{NH}_{3}^{+}$in acidic medium, while it is difficult to dissolve in the alkaline medium. So, as the $\mathrm{pH}$ value increasing, the extraction of copper/ nickel dropped. But $\mathrm{pH}$ less than 3 would no longer lead the result, for Jianzhen Yu \& Dong Klarup evident that when the $\mathrm{pH}$ of the EDTA solution decreased to a certain value all metals that were tested were removed to a greater extent from the sediment. [26] Linn and Elliott (1988) obtained similar results with nitrilotriacetic acid (NTA). High concentrations of $\mathrm{H}_{3} \mathrm{O}^{+}$effectively compete with the metal ions for adsorption sites, as well as assisting the dissolution of mineral phases [29].

\subsection{Influence of Chitosan Concentration}

Different concentrations of chitosan were used and the extraction results are shown in Figure 4. The removal of copper and nickel increased with increasing chitosan concentration from 0.1 to $0.4 \mathrm{~g} / \mathrm{L}$, but the increase was not proportional. The removal of nickel was $56.22 \%$,

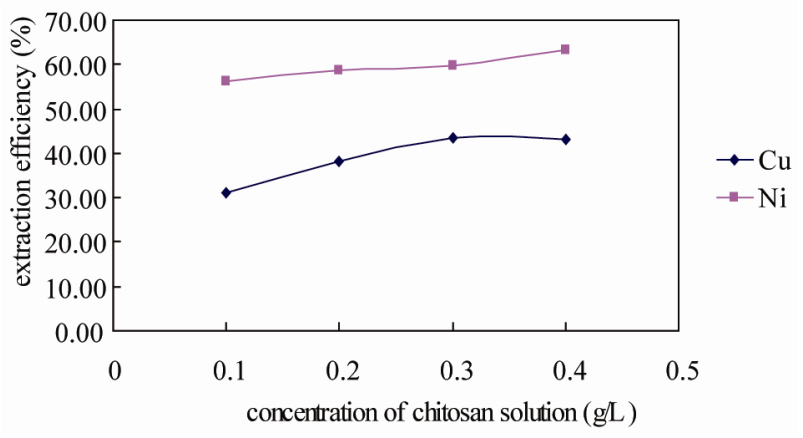

Figure 4. Extraction efficiency of different concentrations of chitosan solution (liquid/solid $=10$, reaction time $=2 \mathrm{~h}, \mathbf{p H}$ = 3.27). 
$58.50 \%, 59.72 \%$, and $63.34 \%$ when the concentration was $0.1,0.2,0.3$, and $0.4 \mathrm{~g} / \mathrm{L}$, respectively. The removal of copper was obviously increased from $30.99 \%$ to $43.49 \%$, when the chitosan concentrate increased from 0.1 to $0.3 \mathrm{~g} / \mathrm{L}$, and then reached a constant level at around $43 \%$. These results indicated that chitosan concentration had effect on the removal efficiency of copper and nickel. But when the dose of chelant was enough for the requirement of soil, the influence was very slight. The critical level of this study was $0.3 \mathrm{~g} / \mathrm{L}$ soil (liquid/ solid $=10$, reaction time $=2 \mathrm{~h}$ ).

\subsection{Influence of Liquid/Solid Ratio}

Copper and nickel extraction efficiencies for different solution/soil ratios are present in Figure 5. Extraction time for these experiments was 2 hours. The figures showed that the extraction efficiencies of copper and nickel were greatly depended on liquid/solid ratio. When the solution/soil ratio increased from 5 to 20 , the removal of copper was from $26.34 \%$ to $47.22 \%$, while the removal of nickel was from $41.75 \%$ to $66.13 \%$. However, with the same concentration $(0.2 \mathrm{~g} / \mathrm{L})$, increasing the liquid/soil ratio means the chitosan dose was increased. It seems that when increasing the chitosan dose, only a small portion was effectively transformed into metalchelant complexes, while the excess remained in free form or might form complexes with other cations ( $\mathrm{Fe}, \mathrm{Al}$, etc.).On the other hand, the extraction process of soil wash would generate large amount of wastewater, which would enhance the treatment cost with chemical extraction technology.

Using a highly concentrated chelating agent could increase the extraction efficiency of heavy metals and likely reduce the generation of leachate [32]. But using a lower concentration and high liquid/soil ratio also has some advantages, especially for some soils, it could prevent clogging of the soil during leaching [33].

\section{Conclusions}

Based on the experimental results, it was shown that the

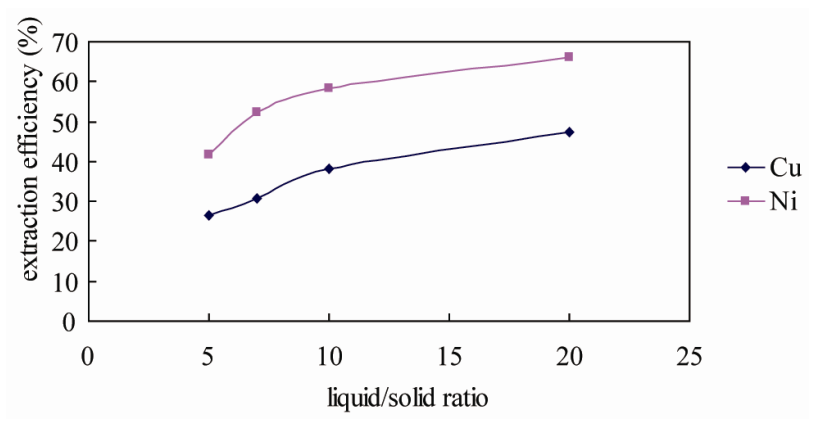

Figure 5. Extraction efficiency of copper/nickel using 0.2 $\mathrm{g} / \mathrm{L}$ chitosan solution with different liquid/solid ratios (reaction time $=2 \mathrm{~h}, \mathrm{pH}=3.27$ ). order of extract efficiency of copper and nickel from the contaminated soil was chitosan $>$ EDTA $>$ sodium citrate, so chitosan solution was the best extracting solution in the three chelating agents. In the different reaction time, results of the experiments showed that extending reaction time could not increase the extraction rate of copper and nickel. Conversely, long reaction time would improve the chance of the extracted heavy metal being re-dissolved in the soil. On the other hand, decreasing the $\mathrm{pH}$ value of eluents could maximize extraction. Acidic condition would increases the mobility of heavy metal. When the $\mathrm{pH}$ value of the chitosan reaction was maintained in the rage of $3-3.5$, the average extraction rate of copper were $43.36 \%$ and of nickel were $37.07 \%$, which had extracted all of the exchangeable metal in the soil, for the share of exchangeable copper was $31.95 \%$ and exchangeable nickel was $29.53 \%$ (Figure 1). The concentration of chitosan solution had effect on the removal efficiency of copper and nickel. But when the dose of chelant was enough for the requirement of soil, the influence was very slight. At the same time, the liquid/solid ratio was an important parameter to control the extracting reaction. But the higher liquid/solid ratio would generate wastewater and increase the cost of soil remediation. In this study, the best match of concentration and liquid/solid was $0.3 \mathrm{~g} / \mathrm{L}$ and $10 \mathrm{~mL} / \mathrm{g}$.

\section{Acknowledgements}

The authors would like to sincerely express their appreciation to the staff members of JDL Environmental Protection Ltd and Professor Zhongping Wang for their help and considerations for the experiment.

\section{REFERENCES}

[1] Q. X. Zhou and Y. F. Song, "Remediation of Contaminated Soils: Principles and Methods," Science Press, Beijing, 2004.

[2] S. A. Aboulroos, M. I. D. Helal and M. M. Kamel, "Remediation of $\mathrm{Pb}$ and $\mathrm{Cd}$ Polluted Soils Using in Situ Immobilization and Phytoextraction Techniques," Soil Sediment Contaminated, Vol. 15, No. 2, 2006, pp. 199215. doi:10.1080/15320380500506362

[3] S. B. Chen, Y. G. Zhu and Y. B. Ma, "The Effect of Grain Size of Rock Phosphate Amendment on Metal Immobilization in Contaminated Soils," Hazardous Materials, Vol. 134, No. 1-3, 2006, pp. 74-79.

doi:10.1016/j.jhazmat.2005.10.027

[4] C. N. Mulligan, R. N. Yong and B. F. Gibbs, "An Evaluation of Technologies for the Heavy Metal Remediation of Dredged Sediments," Hazardous Materials, Vol. 85, No. 1-2, 2001, pp. 145-163. doi:10.1016/S0304-3894(01)00226-6

[5] U.S. Environmental Protection Agency, “Arsenic Treatment Technologies for Soil, Waste, and Water," National 
Service Center for Environmental Publications (NSCEP), EPA-542-R-02-004, Cincinnati, OH, 2002, pp. 1-132.

[6] T. A. Martin, and M. V. Ruby, "In Situ Remediation of Arsenic in Contaminated Soils," Remediation, Vol. 14, No. 1, 2003, pp. 21-32. doi:10.1002/rem.10092

[7] G. Dermont, M. Bergeron, G. Mercier and M. RicherLafl'eche, "Soil Washing for Metal Removal: A Review of Physical/Chemical Technologies and Field Applications," Hazardous Materials, Vol. 152, No. 1, 2008, pp. 1-31. doi:10.1016/j.jhazmat.2007.10.043

[8] Stegmann, R., Brunner, G., Calmano, W. and Matz, G. "Treatment of Contaminated Soil, Fundamentals Analysis Applications. Springer-Verlag," Berlin, Germany, 2001, p. 658.

[9] U.S. Environmental Protection Agency, "Manufacturers to Use New Wood Preservatives," 2002.

http://www.epa.gov/pesticides/factshssts/chemicals/ccatra nsition.htm.

[10] D. R. Lovley and J. D. Coates, "Bioremediation of Metal Contamination," Current Opinion in Biotechnology, Vol. 8, No. 3, 1997, pp. 285-289. doi:10.1016/S0958-1669(97)80005-5

[11] K. Bosecker, "Microbial LEACHING in Environmental Clean-Up Programmes," Hydrometallurgy, Vol. 59, No. 2-3, 2001, pp. 245-248. doi:10.1016/S0304-386X(00)00163-8

[12] R. Chatain, F. Bayard, P. Sanchez, P. Moszkowicz and R. Gourdon, "In Biochemical Leaching of Arsenic in a Mining Soil under Anaerobic Conditions," Proceedings of the 2nd European Bioremediation Conference, Chania, Crete, 30 June -4 July 2003, pp. 308-311.

[13] U.S. Environmental Protection Agency, "Treatment of Arsenic Residuals from Drinking Water Removal," EPA/ 600/R-01/033, Cincinnati, OH, 2001, pp. 1-85.

[14] J. J. Hong, S. M. Yang, Y. K. Choi and C. H. Lee, "Precipitation of Tricarboxylic Acid Biosurfactant Derived From Spiculisporic Acid with Metal Ions in Aqueous Solution," Colloid and Interface Science, Vol. 173, No. 1, 1995, pp. 92-103. doi:10.1006/jcis.1995.1301

[15] O. Schramel, B. Michalke and A. Kettrup, "Study of the Copper Distribution in Contaminated Soils of Hop Fields by Single and Sequential Extraction Procedures," The Science of the Total Environment, Vol. 263, No. 1-3, 2000, pp. 11-22. doi:10.1016/S0048-9697(00)00606-9

[16] K. R. Reddy and S. Chinthamreddy, "Comparison of Extractants for Removing Heavy Metals from Contaminated Clayey Soils," Soil and Sediment Contamination, Vol. 9, No. 5, 2000, pp. 449-462. doi:10.1080/10588330091134347

[17] B. Sun, F. J. Zhao, E. Lombi and S. P. McGrath, "Leaching of Heavy Metals from Contaminated Soils Using EDTA," Environmental Pollution, Vol. 113, No. 2, 2001, pp. 111-120. doi:10.1016/S0269-7491(00)00176-7

[18] B. E. Reed, P. C. Carriere and R. Moore, "Flushing of a $\mathrm{Pb}$ (II) Contaminated Soil Using $\mathrm{HCl}$, EDTA and $\mathrm{CaCl}_{2}$," Environmental Engineering, Vol. 122, No. 1, 1996, pp.
48-50. doi:10.1061/(ASCE)0733-9372(1996)122:1(48)

[19] W. A. Norvell, "Comparison of Chelating Agents as Extractants for Metals in Diverse Soil Materials," The 48th conference of Soil Science Society of America, Las Vegas, 25-30 November 1984, pp. 1285-1292.

[20] H. A. Elliott and G. A. Brown, "Comparative Evaluation of NTA and EDTA for Extractive Decontamination of Pb-Polluted Soils," Water Air and Soil Pollution, Vol. 45, No. 3-4, 1989, pp. 361-369. doi:10.1007/BF00283464

[21] C. Kim, S. K. Ong, "The Selective Reaction of Lead and Amorphous Iron with EDTA in Lead Sulfate-Contaminated Soil System," Environmental Engineering Research, Vol. 3, No. 3, 1998, pp. 167-174.

[22] R. W. Peters, "Chelant Extraction of Heavy Metals from Contaminated Soils," Hazardous Materials, Vol. 66, No. 1-2, 1999, pp. 151-210. doi:10.1016/S0304-3894(99)00010-2

[23] J. W. Neilson, J. F. Artiola and R. M. Maier, "Characterization of Lead Removal from Contaminated Soils by Nontoxic Soil-Washing Agents," Environmental Quality, Vol. 32, No. 3, 2003, pp. 899-908. doi: $10.2134 / \mathrm{jeq} 2003.0899$

[24] C. C. Lee and W. D. Marshall, "Recycling of ComPlexometric Extractants to Remediate a Soil Contaminated with Heavy Metals," Environmental Monitoring, Vol. 4, No. 2, 2003, pp. 325-329.

[25] A. Tessier, P. G. C. Campell and M. Bisson, "Sequential Extraction Procedure for the Speciation of Particulate Trace Metals," Analytical Chemistry, Vol. 51, No. 7, 1979, pp. 844-851. doi:10.1021/ac50043a017

[26] Y. J. and D. Klarup, "Extraction Kinetics of Copper, Zinc, Iron, and Manganese from Contaminated Sediment Using Disodium Ethylenediaminetraacetate," Water Air and Soil Pollution, Vol. 75, 1994, pp. 205-225

[27] M. M. Benjamin and J. O. Leckie, "Multiple-Site Adsorption of $\mathrm{Cd}, \mathrm{Cu}, \mathrm{Zn}$, and $\mathrm{Pb}$ on Amorphous Iron Oxyhydroxide," Colloid and Interface Science, Vol. 79, No. 1, 1981, pp. 209-221.

[28] J.-F. Peng, Y.-H. Song, P. Yuan, X.-Y. Cui and G.-L. Qiu, "The Remediation of Heavy Metals Contaminated Sediment," Hazardous Materials, Vol. 161, No. 2-3, 2009, pp. 633-640

[29] J. H. Linn, and H. A. Elliott "Mobilization of $\mathrm{Cu}$ and $\mathrm{Zn}$ in Contaminated Soil by Nitrilotriacetic Acid," Water, Air, and Soil Pollution, Vol. 37, No. 3-4, 1988, pp. 449-458. doi:10.1007/BF00192954

[30] H. E. Allen and P. H. Chen,"Remediation of Metal ConTaminated Soil by EDTA Incorporating Electrochemical Recovery of Metal and EDTA," Environmental Progress, Vol. 12, No. 4, 1993, pp. 284-292. doi:10.1002/ep.670120409

[31] R. W. Peters and L. Shem, "Use of Chelating Agents for Remediation of Heavy Metal Contaminated Soil," Environmental Remediation: Removing Organic and Metal Ion Pollutants, Washington, DC, 1992, pp. 70-84. doi:10.1021/bk-1992-0509.ch006 
[32] M. D. Andrade, S. O. Prasher and W. H. Hendershot, "Optimizing the Molarity of a EDTA Washing Solution for Saturated-Soil Remediation of Trace Metal Contaminated Soils," Environmental Pollution, Vol. 147, No. 3, 2007, pp. 781-790.

doi:10.1016/i.envpol.2006.07.010
[33] M. A. M. Kedziorek, A. Dupuy and A. C. M. Bourg, "Leaching of $\mathrm{Cd}$ and $\mathrm{Pb}$ from Polluted Soil during the Percolation of EDTA: Laboratory Column Experiments Modeled with a Non-Equilibrium Solubilization Step,' Environmental Science and Technology, Vol. 32, No. 11, 1998, pp. 1609-1614. 